\title{
MiR-146a-5p and miR-191-5p are the Candidates for Novel Diagnostic Markers of Ovarian Clear Cell Carcinoma
}

\author{
Shigeatsu Takamizawa \\ Tokyo Medical University \\ Junya Kojima \\ Tokyo Medical University \\ Tomohiro Umezu \\ Tokyo Medical University \\ Masahiko Kuroda \\ Tokyo Medical University \\ Shigehiro Hayashi \\ Tokyo Medical University

\section{Takenori Maruta} \\ The Jikei University School of Medicine

\begin{abstract}
Aikou Okamoto
The Jikei University School of Medicine

Hirotaka Nishi ( $\nabla$ nishih@tokyo-med.ac.jp)
\end{abstract} \\ Tokyo Medical University
}

\section{Research Article}

Keywords: ovarian cancer, malignant, endometrioma, endometriosis, non-invasive, sensitivity, specificity, receiver operating characteristic curve, CA125

Posted Date: December 14th, 2021

DOI: https://doi.org/10.21203/rs.3.rs-1160869/v1

License: (1) This work is licensed under a Creative Commons Attribution 4.0 International License.

Read Full License 


\section{Abstract}

Background: Ovarian cancer is a malignant gynecologic disease rarely diagnosed in the early stages. Among ovarian cancers, clear cell carcinoma has a poor prognosis due to its malignant potential. MicroRNAs (miRNAs) regulate gene expression in cells by suppressing the translation of the target gene or by degrading the target mRNA. They are also secreted from the cells in the blood, binding to the proteins or included in extracellular vesicles lipids and assisting in cell-cell communication. Hence, the serum miRNAs can also be diagnostic biomarkers for ovarian cancer. This study investigated and identified specific miRNAs for ovarian cancer clear cell carcinoma and compared them to those of the ovarian endometrioma in healthy controlpatients.

Results: CA125, an ovarian tumor marker, did not differ between ovarian clear cell carcinoma, endometriosis, and healthy controlsthe three groups. Four miRNAs (miR-146a-5p, miR-191-5p, miR-484, and miR-574-3p) were analyzed. The miR-146a-5p and miR-191-5p expression levels were significantly increased in the serum samples from the ovarian clear cell carcinoma subjects compared to the healthy controlscontrols, but not in the subjects with endometriosis $(P<0.05)$. Furthermore, the bioinformatics analysis showed that $C C N D 2$ and $N O T C H 2$ were the candidate target genes of miR-146a-5p and miR-191$5 p$.

Conclusions: Our results showed that miR-146a-5p and miR-191-5p might be useful as an early and noninvasive diagnostic tool in ovarian clear cell carcinoma. These miRNAs can help in distinguishing between ovarian clear cell carcinoma and ovarian endometrioma. To the best of our knowledge, no studies have screened any candidates specifically for clear cell carcinoma.

\section{Background}

Ovarian cancer accounts for the highest fatality among gynecological malignancies with an increasing number of patients worldwide [1]. Ovarian cancer accounts for $2.5 \%$ of all malignancies in women, but $5 \%$ of all deaths due to cancer because four out of five patients are diagnosed at an advanced stage [2]. For advanced-stage ovarian cancer, patients have achieved the best outcomes via complete resection of the diseased tissues and combination chemotherapy [3]. However, the 5-year survival rate of advanced ovarian cancer (stages III and IV) was only about $20 \%$ and was considered to have the poorest prognosis among female genital malignancies [4].

Histopathologically, ovarian cancer comprises five major subgroups: clear cell, endometrioid, mucinous, high-grade serous, and low-grade serous. Among them, clear cell carcinoma is common in Japanese patients, but the etiology is still unclear. This group of ovarian cancer is more resistant to the standard platinum and paclitaxel chemotherapy than the other advanced serous ones [5]. Hence, the prognosis for advanced clear cell ovarian cancer is poor, compared to that of early-stage ovarian cancer [4]. This necessitates the early diagnosis of clear cell ovarian carcinoma. To date, there has been no specific test for the diagnosis of early-stage ovarian cancer. The patients suspected of ovarian cancer are 
conventionally tested using transvaginal sonography and tumor markers, such as CA125. CA125 assessment is the standard method for diagnosis, following response to treatment, for predicting the prognosis in ovarian cancer like clear cell carcinoma [6]. The level of this marker does not increase at an early stage and is not increased in the ovarian clear cell carcinoma, as reported previously [7]. To date, no studies have screened any candidates specifically for clear cell carcinoma.

Extracellular RNA, including serum microRNAs (miRNAs), has received much attention recently. MiRNAs comprise small non-coding RNAs of 20-25 nucleotides that regulate gene expression in cells by suppressing the translation of the target gene or by degrading the target mRNA [8]. The miRNAs secreted from cells are stably present in body fluids in extracellular vesicles containing exosomes or bind to the proteins or lipids [9] playing an important role in cell-cell communication [10]. Many studies have reported serum miRNAs as promising biomarkers for various diseases because they reflect physiological and pathological states $[11,12,13]$.

There are some ovarian clear cell carcinoma-specific miRNAs. Recently, Ochiya et al. reported some miRNAs to be specific to ovarian cancer [14]. On the other hand, histopathological examination revealed endometriosis prevalent in middle-aged women to be associated with the risk of ovarian cancer. Similarly, ovarian endometrioma is associated with the risk of endometriosis-associated ovarian cancer, especially clear cell carcinoma $[15,16]$.

Clinically, it is difficult to distinguish between ovarian endometriosis and clear cell carcinoma because of the evident similarities on ultrasound and increasing CA125 levels in both endometrioma and clear cell carcinoma. In this report, we independently investigated and explored the specific miRNAs in the clear cell carcinoma compared to the ovarian endometrioma and healthy controls.

\section{Methods}

\section{Study design}

The present study was approved by the internal review boards of the Tokyo Medical University. The written informed consent was obtained from all the patients before the collection of specimens, according to the Declaration of Helsinki. The patient backgrounds were obtained through interviews. The blood samples were collected before operation, chemotherapy, and radiation therapy. The ovarian clear cell carcinoma and endometriosis were diagnosed based on the histological examinations.

A total of 64 subjects participated in the research conducted at the Tokyo Medical University Hospital from February 2010 to January 2019 and at the Jikei University School of Medicine between August 2008 and November 2011. 29 patients had ovarian clear cell carcinoma, 17 had endometriosis, and 18 were healthy controls. The patients were diagnosed with ovarian clear cell carcinoma, 6 with stage la, 5 with stage Ic1, 5 with stage IC2, 2 with stage IC3, 1 with stage Ila, 2 with stage IIb, 1 with stage IIla 1, 4 with stage IIIb, 2 with stage IIIc, and 1 with stage IVb. 


\section{Serum preparation and total RNA extraction}

The blood samples were collected from the patients with ovarian clear cell carcinoma, and endometriosis, as well as from the healthy controls. We measured the CA125 levels in patients with endometriosis and ovarian cancer before surgery. The blood serum was separated by centrifugation at $400 \mathrm{xg}$ for $10 \mathrm{~min}$ and stored at $-80^{\circ} \mathrm{C}$. The total RNA was extracted from the serum using the miRNeasy Serum/Plasma Advanced Kit (Qiagen, Hilden, Germany) according to the manufacturer's protocol.

\section{Search for candidate miRNAs with TaqMan Array Human microRNA Cards}

We used TaqMan ${ }^{\text {TM }}$ Array Human MicroRNA A+B Cards Set v3.0 (Thermo Fisher Scientific, Inc.) to search for candidate miRNAs in 20 samples (16 samples of ovarian clear cell carcinoma and four healthy controls). Using a volcano plot, we identified target miRNAs with significantly different expression levels in control and ovarian clear cell carcinoma patients. Then, using an amplification plot, we narrowed down the miRNAs that were amplified in almost all targets. Finally, we determined the target miRNAs based on relative gene expression.

\section{miRNA expression analysis by $q P C R$ and receiver operating characteristic curves}

Four miRNAs (miR-146a-5p, miR-191-5p, miR-484, and miR-574-3p) were analyzed by the TaqMan miRNA expression analysis (Thermo Fisher Scientific, Inc.) and real-time quantitative reverse transcriptasepolymerase chain reaction (qRT-PCR). The expression analyses were performed using the TaqMan Advanced miRNA assays for human miR-146-5p (478399_mir), miR-191-5p (477952_mir), miR-484 (478308_mir), miR-574-3p (478163_mir), and miR-16 (477860_mir) as an endogenous control [17]. The cDNA was synthesized using the TaqMan Advanced miRNA cDNA Synthesis Kit (Thermo Fisher Scientific, Inc.).

Quantitative PCR (qPCR) was performed with RT primers using the Universal Master Mix and specific miRNAs using the Applied Biosystems StepOnePlus ${ }^{\text {TM }}$ real-time PCR system (Thermo Fisher Scientific, Inc.). The sequence detection was performed according to the manufacturer's protocol.

The reaction mixtures were incubated at $95^{\circ} \mathrm{C}$ for $2 \mathrm{~min}$, followed by 40 cycles at $95^{\circ} \mathrm{C}$ for $15 \mathrm{~s}$ and $60^{\circ} \mathrm{C}$ for $1 \mathrm{~min}$. The miRNA expression levels in subjects with ovarian clear cell carcinoma and endometriosis compared to healthy controls were calculated using the comparative $2^{-\Delta \Delta \mathrm{Ct}}$ method $[18,19]$. Receiver operating characteristic (ROC) curves were generated using the miR-146a miR-191 expression profile. The graphical plots of the true and false positive rates are shown. The area under the ROC curve represents the identification accuracy.

\section{Statistical analysis}

The statistical analyses of the causal association between the clinical background, the expression level of the miRNAs, and the ROC curve analysis were performed using SPSS-27 software. The statistical significance was determined by a Kruskal-Wallis test with significance set at $P<0.05$. 


\section{Analysis of miRNA 146a-5p and miRNA 191-5p MiRTarBase}

Subsequent to the identification of differentially expressed miRNAs, the predicted target genes for these altered miRNAs were subjected to experimental validation using the miRNA-target interaction database MiRTarBase (http://mirtarbase.cuhk.edu.cn/php/index.php) [20].

\section{Results}

\section{Characteristics of the subjects}

Of the 64 subjects, 18 were healthy controls, 17 had endometriosis, and 29 had ovarian cancer. The mean age of all patients was 47.5 years (range 31-82 years), mean age for endometriosis patients was 35 years (range 22-56 years), and mean age for ovarian clear cell carcinoma patients was 53 years (range 31-81 years). Table 1 shows the clinical characteristics and the values of CA125 in the patients with ovarian clear cell carcinoma (One patient did not check CA125 before the operation).

Table 2 shows the clinical characteristics and the value of CA125 in patients with endometriosis. CA125 varied differently in each endometriosis and ovarian clear cell carcinoma patients.

\section{Identifying the candidate miRNAs}

Based on the volcano plot, 18 miRNAs were identified (Fig. 1). In the amplification plot, 7 miRNAs (mir146a-5p, mir-191-5p, mir-223-3p, mir-24-3p, mir-320a-3p, mir-484, 574-3p) were confirmed as amplified. The results of gene expression analysis showed that hsa-miR-191-5p and hsa-miR-574-3p were more than 100-fold differentially expressed in the carcinoma patients compared to the controls. Differential expression was also observed for hsa-miR-146a-5p and hsa-miR-24-3p (Fig. 2). Among the 16 samples of ovarian clear cell carcinoma, 12 samples with similar miRNA amplification were again analyzed using a volcano plot, and four miRNAs (mir-146a-5p, mir-191-5p, mir-484, 574-3p) were listed.

\section{miRNA expression status in ovarian clear cell carcinoma}

The expression of miR-484 and miR-574-3p were not different among the three groups. However, the miR146a-5p and miR-191-5p expression levels were significantly increased in the serum samples from the ovarian clear cell carcinoma subjects compared to the healthy controls, but not in the subjects with endometriosis $(P<0.05)$.

The median serum miR-146a-5p expression level was 0.72 in the healthy controls, 0.57 in the endometriosis subjects, and 4.42 in the ovarian clear cell carcinoma patients, respectively $(P<0.01$, Fig. 3, Kruskal-Wallis test).

The ROC curve showed that the miR-146a-5p serum levels may differentiate the ovarian clear cell carcinoma patients from the healthy controls, and the ROC curve area was 0.762 (95\% confidence interval: 0.629-0.896, Fig. 4). 
When the cut-off value was 0.652 (relative expression value), miR-146a-5p was $79.3 \%$ sensitive to the ovarian clear cell carcinoma and $50.0 \%$ specific compared to the healthy controls. In contrast, the median serum miR-191-5p expression level was 0.833 in the healthy controls, 1.00 in the endometriosis subjects, and $3.58 \%$ in the ovarian clear cell carcinoma patients $(P<0.01$, Fig.5, Kruskal-Wallis test). The ROC curve showed that the miR-191-5p serum levels may differentiate the ovarian clear cell carcinoma patients from healthy controls, and the ROC curve area was 0.830 (95\% confidence interval: 0.7140.945 ) (Fig. 6). When the cut-off value was 0.723 (relative expression value), the miR-191-5p was $89.7 \%$ sensitive to ovarian clear cell carcinoma and $50.0 \%$ specific compared to the healthy controls. Comparing by cancer stage, the expression of miR-146a-5p and miR-191-5p was not different.

The MiRTarBase was used to identify the predicted target genes of miR-146a-5p and miR-191-5p to determine their biological significance. More than 50 target genes were extracted by the MiRTarBase, and the target genes that showed strong evidence are summarized in Additional file 1. The CCND2 and NOTCH2 genes were the candidate targets of miR-146a-5p and miR-191-5p.

\section{Discussion}

The early detection of cancer may contribute to improved patient survival rates. Biomarkers that can be used to detect cancer at an early stage are important for the diagnosis and prognosis of cancer.

This study aimed to investigate the novel miRNAs in ovarian clear cell carcinoma. As previously reported, CA125 levels were not distinguishable between endometriosis and clear cell carcinoma [21]. The expression levels of miR-146a-5p and miR-191-5p were significantly elevated in the patients with the ovarian clear cell carcinoma in the three groups. In the ROC analysis, miR-146-5p and miR-191-5p revealed around 0.8 sensitivity for ovarian clear cell carcinoma. This indicated that miR-146-5p and miR191-5p were useful for exclusion diagnosis.

Using bioinformatics analysis, MiRTarBase showed that the CCND2 and NOTCH2 genes were the candidate targets of miR-146a-5p and miR-191-5p (Additional file 1). CCND2 belongs to the cyclin family, which functions in cell cycle progression [22]. CCND2 forms a complex with the cyclin-dependent kinase CDK4 or CDK6 and functions as the regulatory subunit of the complex, whose activity is required for the cell cycle G1/S transition [23]. As CCND2 shortens the G1 phase and participates in cell progression, the CCND2 gene is suspected to be involved in cancer cell growth [24].

Several studies have demonstrated that CCND2 is associated with tumorigenesis [25]. Chang et al. revealed that CCND2 is involved in stimulating the proliferation, cell cycle progression, migration, and invasion of ovarian cancer cells [26]. NOTCH2 promotes cell proliferation and epithelial-mesenchymal transition in the epithelial ovarian cancer cell lines [27]. MiR-146-5p and MiR-191-5p may be upregulated in the ovarian cancer patients to inhibit the function of $\mathrm{NOTCH} 2$ and prevent the progression of ovarian cancer. 
Our results showed that CCND2 and NOTCH2 are the candidates for both miRNAs. Thus, it was hypothesized that in ovarian cancer clear cell carcinoma patients, miR-146-5p and miR-191-5p were upregulated to inhibit the function of CCND2 and NOTCH2.

A major limitation of this study was small sample size. We would research larger samples in the future.

\section{Conclusions}

Our results showed that miR-146a-5p and miR-191-5p may be useful as an early and non-invasive diagnostic tool in the search for ovarian clear cell cancer. These miRNAs can also distinguish between ovarian clear cell carcinoma and ovarian endometrioma.

\section{Abbreviations}

miRNA, microRNA, qRT-PCR, real-time quantitative reverse transcriptase-polymerase chain reaction, qPCR, quantitative PCR, ROC, receiver operating characteristic

\section{Declarations}

\section{Acknowledgments}

We thank the Tokyo Medical University and the staff at the Department of Obstetrics and Gynecology, Tokyo Medical University, for their technical and administrative assistance.

\section{Funding}

This study was funded by Grant-in-Aid for Scientific Research (C) (15K10733).

\section{Authors' contributions}

ST, JK, and TU performed data analysis. ST, JK, HN, and SH collected the samples. ST performed the experiments. ST and JK wrote the manuscript.

\section{Ethics approval and consent to participate}

The patient data were used according to the ethical principles of the Declaration of Helsinki. The study protocol was approved by the Regional Ethics Review Board of Tokyo Medical University (Tokyo, Japan), and all patients provided written informed consent before participation.

\section{Consent for publication}

Not applicable.

\section{Competing interests}


The authors declare that they have no competing interests.

\section{Availability of data and materials}

All data generated or analysed during this study are included in this published article [and its supplementary information files].

\section{Authors' information}

Shigeatsu Takamizawa

6-7-1 Nishishinjuku, Shinjuku-ku, Tokyo 160-0023, Japan.

Phone: +81-3-3342-6111

Fax: +81-3-3348-5918

E-mail: takami77@tokyo-med.ac.jp

\section{References}

1. Webb PM, Jordan SJ. Epidemiology of epithelial ovarian cancer. Best Pract Res Clin Obstet Gynaecol. 2017,41:3-14.

2. Howlader N, Noone AM, Krapcho M, Miller D, Brest A, Yu M, Ruhl J, Tatalovich Z, Mariotto A, Lewis DR, Chen HS, Feuer EJ, Cronin KA (eds). SEER Cancer Statistics Review, 1975-2017, National Cancer Institute. Bethesda, MD, 2020. https://seer.cancer.gov/csr/1975_2017/.

3. Landrum LM, Java J, Mathews CA. Prognostic factors for stage III epithelial ovarian cancer treated with intraperitoneal chemotherapy: A Gynecologic Oncology Group study. Gynecol Oncol. 2013,130:12-8.

4. Trimble EL, Christan MC, Korsay C. Surgical debulking plus paclitaxel-based adjuvant chemotherapy superior to previous ovarian cancer therapies. Oncology. 1999,13:1068.

5. del Carmen MG, Birrer M, Schorge JO. Clear cell carcinoma of the ovary: a review of the literature. Gynecol Oncol. 2012,126:481-90.

6. Duffy MJ, Bonfrer JM, Kulpa J, Rustin GJ, Soletormos G, Torre GC, et al. CA125 in ovarian cancer: European Group on Tumor Markers guidelines for clinical use. Int J Gynecol Cancer. 2005,15:67991.

7. Tian C, Markman M, Zaino R, Ozols RF, McGuire WP, Muggia FM, et al. CA-125 change after chemotherapy in prediction of treatment outcome among advanced mucinous and clear cell epithelial ovarian cancers: A Gynecologic Oncology Group Study. Cancer 2009,115:1395-403.

8. Kim VN, Han J, Siomi MC. Biogenesis of small RNAs in animals. Nat Rev Mol Cell Biol. 2009,10:12639. 
9. Kosaka N, Yoshioka Y, Fujita Y, Ochiya T. Versatile roles of extracellular vesicles in cancer. J Clin Invest. 2016,126:1163-72.

10. Kim VN. MicroRNA biogenesis: coordinated cropping and dicing. Nat Rev Mol Cell Biol. 2005,6:37685.

11. Pritchard $\mathrm{CC}$, Cheng HH, Tewari M. MicroRNA profiling: approaches and considerations. Nat Rev Genet. 2012,13:358-69.

12. Cortez MA, Bueso-Ramos C, Ferdin J, Lopez-Berestein G, Sood AK, Calin GA. MicroRNAs in body fluids-the mix of hormones and biomarkers. Nat Rev Clin Oncol. 2011,8:467-77.

13. Nagamitsu Y, Nishi H, Sasaki T, Takaesu Y, Terauchi F, Isaka K. Profiling analysis of circulating microRNA expression in cervical cancer. Mol Clin Oncol. 2016 Jul,5(1):189-194.

14. Yokoi A, Matsuzaki J, Yamamoto Y, Yoneoka Y, Takahashi K, Shimizu H, et al. Integrated extracellular microRNA profiling for ovarian cancer screening. Nat Commun. 2018,9:1-10.

15. Gurung A, Hung T, Morin J, Gilks CB. Molecular abnormalities in ovarian carcinoma: clinical, morphological, and therapeutic correlates. Histopathology. 2013,62:59-70.

16. Grandi G, Toss A, Cortesi L, Botticelli L, Volpe A, Cagnacci A. The association between endometriomas and ovarian cancer: Preventive effect of inhibiting ovulation and menstruation during reproductive life. Biomed Res Int. 2015,2015:751571

17. Schrauder MG, Strick R, Schulz-Wendtland R, Strissel PL, Kahmann L, Loehberg CR, et al. Circulating micro-rnas as potential blood-based markers for early stage breast cancer detection. PLoS One 2012,7:1:e29770.

18. Ohyashiki K, Umezu T, Yoshizawa SI, Ito Y, Ohyashiki M, Kawashima H, Tanaka M, Kuroda M, Ohyashiki JH. Clinical impact of down-regulated plasma miR-92a levels in non-Hodgkin's lymphoma. PLoS One 2011,6:e16408.

19. Schrauder MG, Strick R, Schulz-Wendtland R, Strissel PL, Kahmann L, Loehberg CR, Lux MP, Jud SM, Hartmann A, Hein A, Bayer CM. Circulating micro-RNAs as potential blood-based markers for early stage breast cancer detection. PLoS One 20127: ee29770

20. Huang HY, Lin YC, Li J, Huang KY, Shrestha S, Hong HC, Tang Y, Chen YG, Jin CN, Yu Y, Xu JT, Li YM, Cai XX, Zhou ZY, Chen XH, Pei YY, Hu L, Su JJ, Cui SD, Wang F, Xie YY, Ding SY, Luo MF, Chou CH, Chang NW, Chen KW, Cheng YH, Wan XH, Hsu WL, Lee TY, Wei FX, Huang HD. miRTarBase 2020: updates to the experimentally validated microRNA-target interaction database. Nucleic Acids Research, Volume 48, Issue D1, 08 January 2020, Pages D148-D154.

21. Taniguchi F. New knowledge and insights about the malignant transformation of endometriosis. $J$ Obstet Gynaecol Res. 2017,43:1093-100.

22. Hua M, Qin Y, Sheng M, Cui X, Chen W, Zhong J, et al. miR-145 suppresses ovarian cancer progression via modulation of cell growth and invasion by targeting CCND2 and E2F3. Mol Med Rep. 2019,19:3575-83.

23. Kato JY, Sherr CJ. Inhibition of granulocyte differentiation by G1 cyclins D2 and D3 but not D1. Proc Natl Acad Sci U S A.1993,90:11513-7. 
24. Song H, Hogdall E, Ramus SJ, Dicioccio RA, Hogdall C, Quaye L, et al. Effects of common germline genetic variation in cell cycle genes on ovarian cancer survival. Clin Cancer Res. 2008,14:1090-5.

25. Zhu H, Dougherty U, Robinson V, Mustafi R, Pekow J, Kupfer S, et al. EGFR signals downregulate tumor suppressors miR-143 and miR-145 in Western diet-promoted murine colon cancer: role of G1 regulators. Mol Cancer Res. 2011,9:960-75.

26. Chang L, Guo R, Yuan Z, Shi H, Zhang D. LncRNA HOTAIR regulates CCND1 and CCND2 expression by sponging miR-206 in ovarian cancer. Cell Physiol Biochem. 2018,49:1289-303.

27. Lu S, Liu W, Shi H, Zhou H. Exosomal miR-34b inhibits proliferation and the epithelial-mesenchymal transition by targeting Notch2 in ovarian cancer. Oncol Lett. 2020,20:2721-8.

\section{Tables}

Table 1 Characteristics of patients with ovarian clear cell carcinoma

\begin{tabular}{ll} 
Characteristics & $\begin{array}{l}\text { Ovarian clear cell carcinoma } \\
(\mathbf{n = 2 9})\end{array}$ \\
\hline Age, years & 53 \\
\hline Median & $31-81$ \\
\hline Range & \\
\hline Clinical stage & 6 \\
\hline IA & 5 \\
\hline IC1 & 5 \\
\hline IC2 & 2 \\
\hline IC3 & 1 \\
\hline IIA & 2 \\
\hline IIB & 1 \\
\hline IIIA1 & 4 \\
\hline IIIB & 2 \\
\hline IIIC & 1 \\
\hline IVB & 407 \\
\hline Serum CA125 antigen, $\mathrm{ng} / \mathrm{mL}$ & \\
\hline Median & $13-5877$ \\
\hline Range &
\end{tabular}


Table 2 Characteristics of the patients with ovarian endometriosis

\begin{tabular}{ll} 
Characteristics & $\begin{array}{c}\text { Endometriosis } \\
(\mathbf{n}=17)\end{array}$ \\
\hline Age, years & 35 \\
\hline Median & $22-56$ \\
\hline Range & \\
\hline BMl & 21.6 \\
\hline Median & $17.7-34.7$ \\
\hline Range & \\
\hline tumor size & 62 \\
\hline Median & $30-150$ \\
\hline Range & \\
\hline Serum CA125 antigen, $\mathrm{ng} / \mathrm{mL}$ & 55.1 \\
\hline Median & $10.7-555.6$ \\
\hline Range
\end{tabular}

BMI, body mass index

Figures 


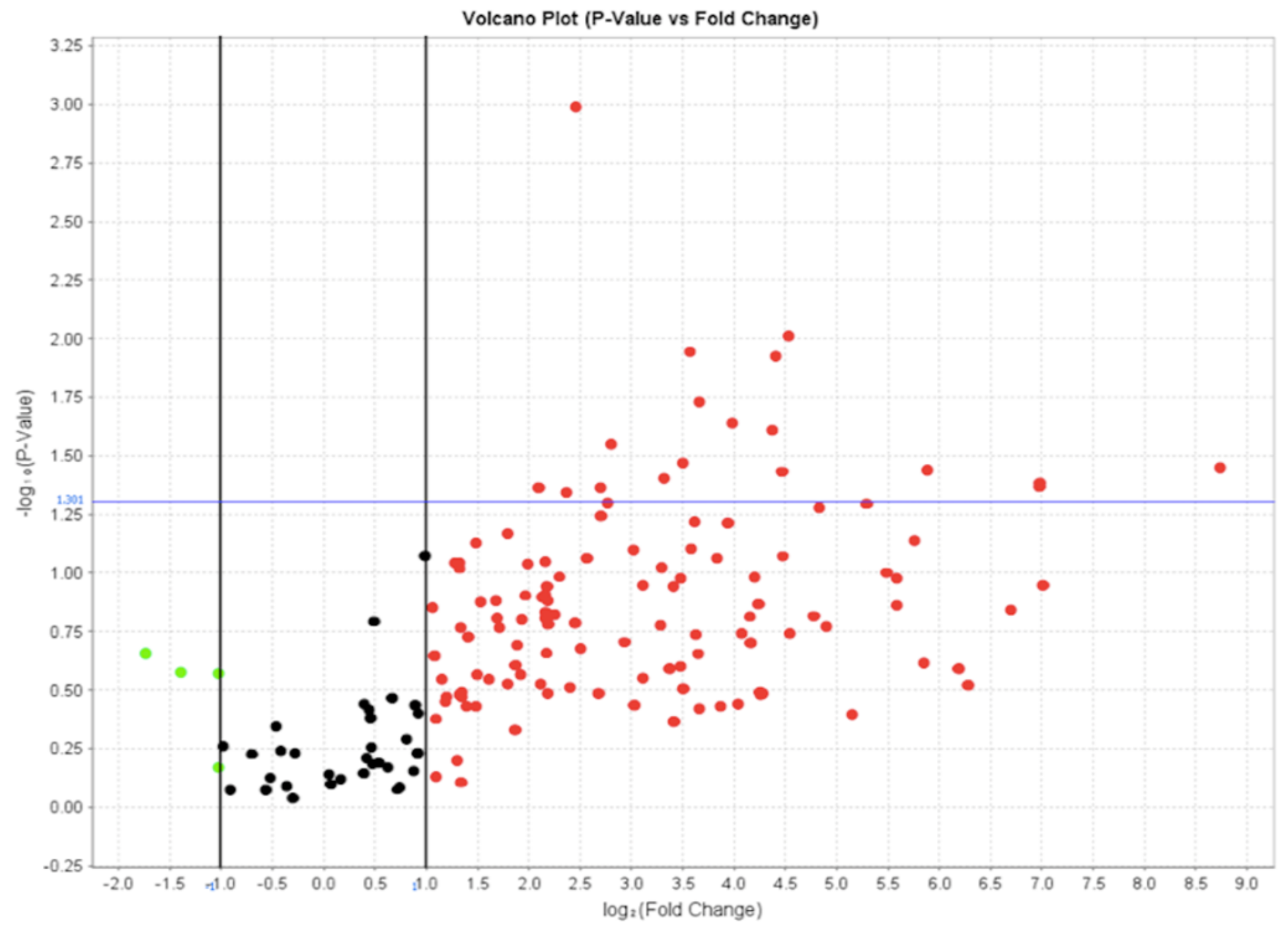

Figure 1

Volcano plot Target miRNAs with significantly different expression levels in healthy controls and ovarian clear cell carcinoma patients were listed. As a result, 18 miRNAs were identified as candidates. 


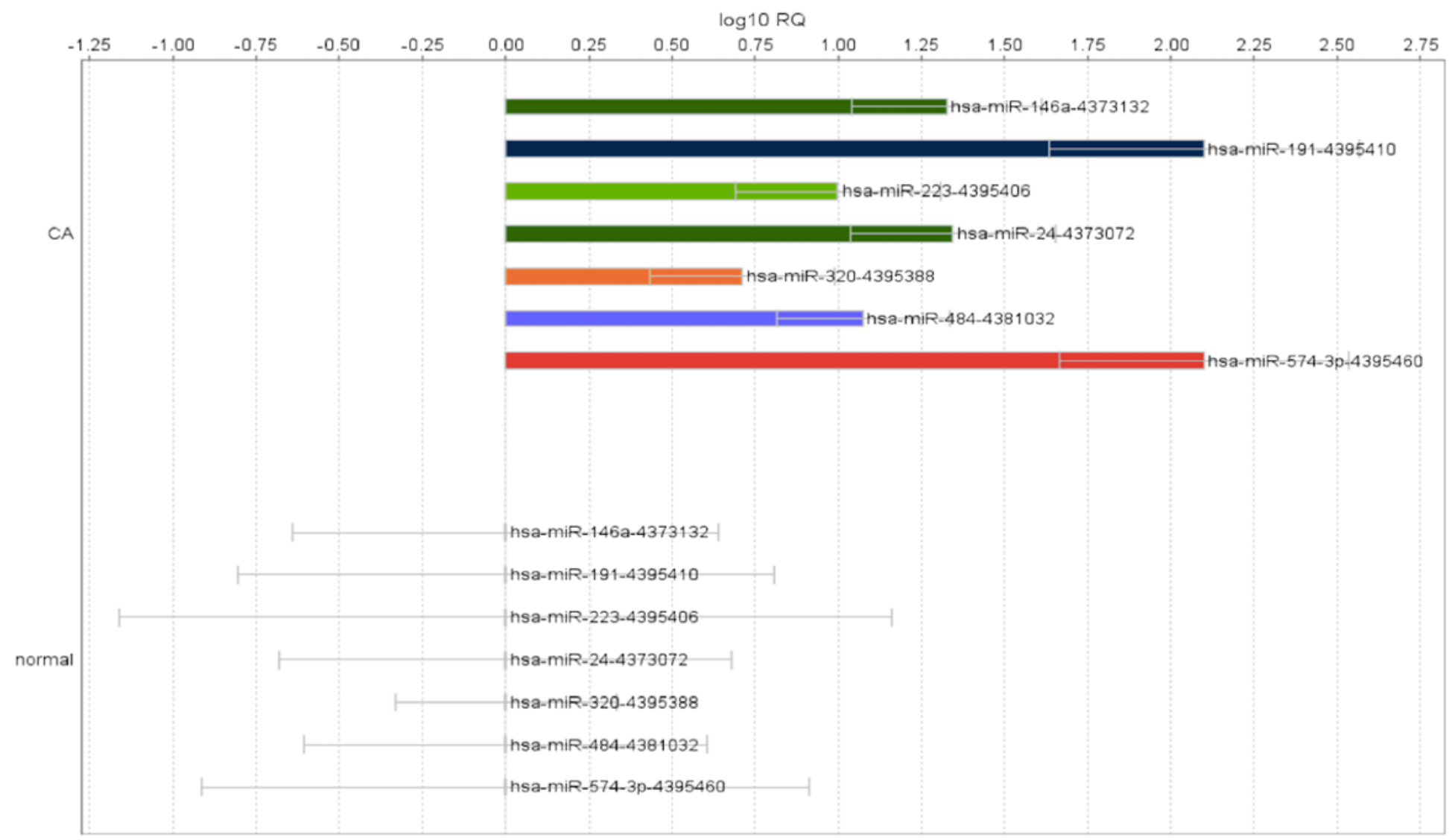

Figure 2

Gene Expression Hsa-miR-191-5p and hsa-miR-574-3p were differentially expressed by more than 100fold compared to the control. Differential expression was also observed for hsa-miR-146a-5p and hsamiR-24-3p. 


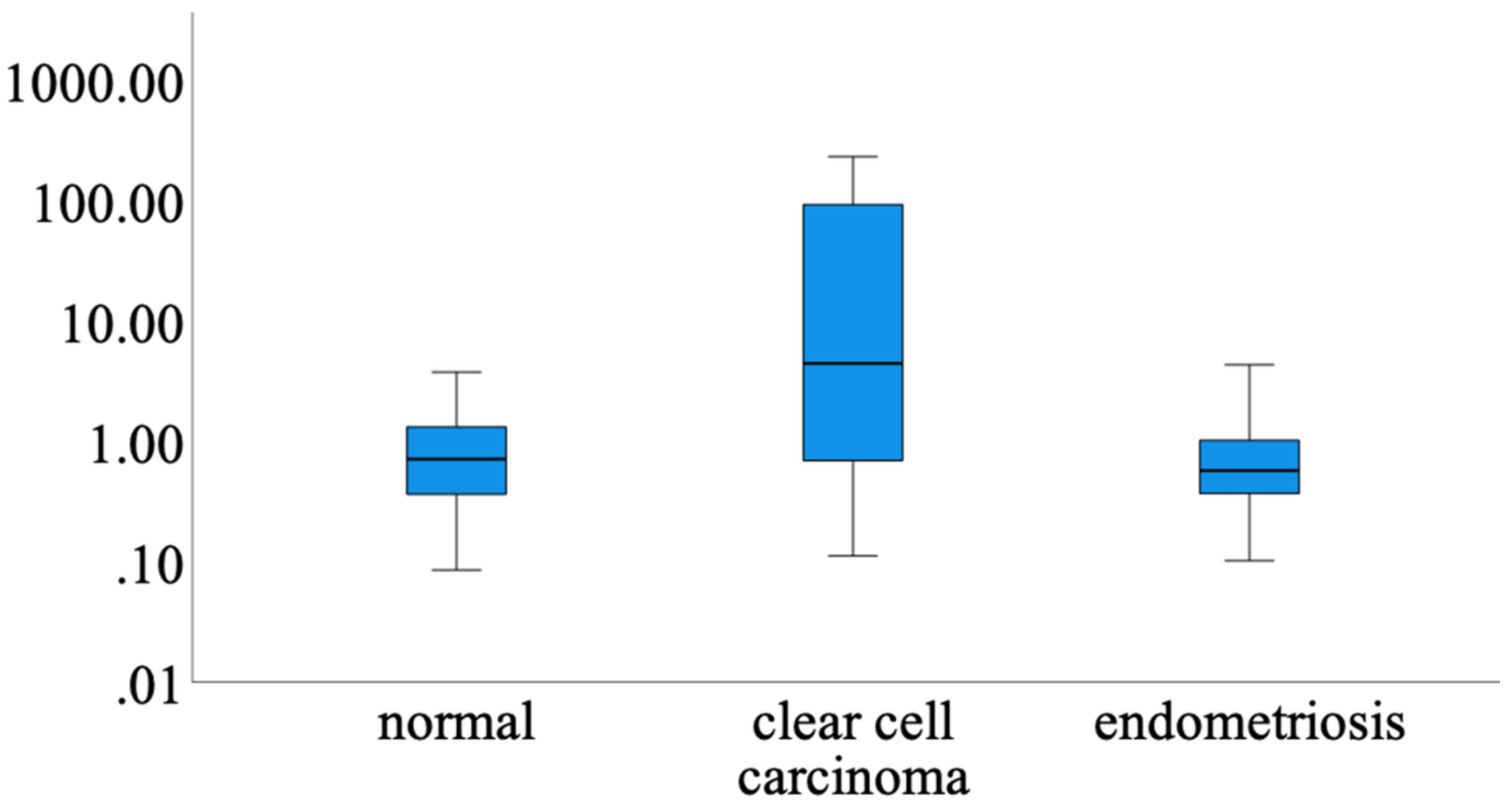

Figure 3

The serum miR 146a-5p expression level in the subjects The serum miR 146a-5p expression levels in the subjects with ovarian clear cell carcinoma and ovarian endometriosis at various stages by a quantitative polymerase chain reaction. The asterisk indicates statistical difference $(P<0.05)$ is significant. 


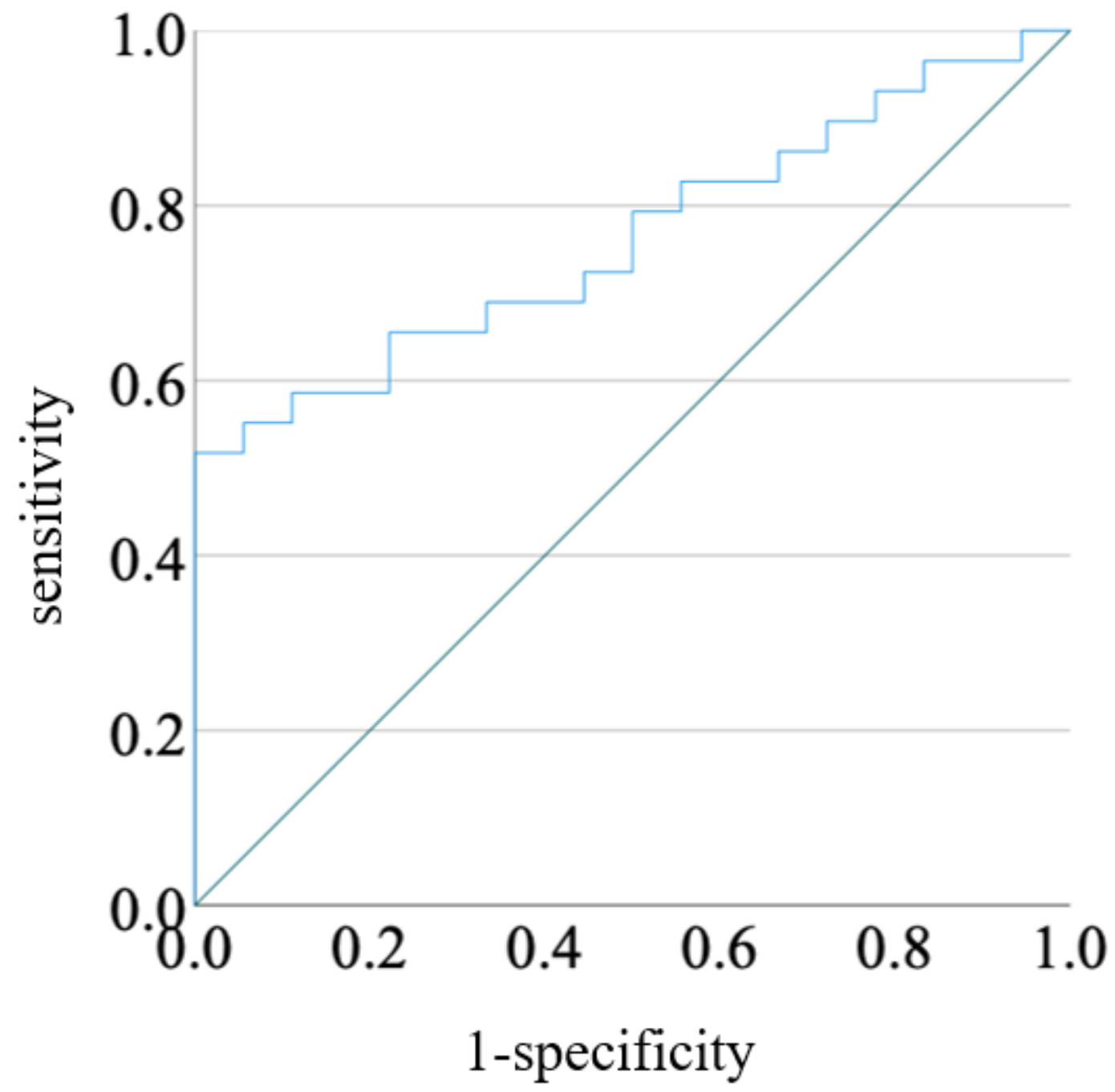

Figure 4

ROC for miR-146a-5p in the normal and ovarian clear cell carcinoma The area under the receiver operating characteristic curve for miR $146 \mathrm{a}-5 \mathrm{p}$ based on quantitative polymerase chain reaction data. The cut-off level of plasma miR $146 a-5 p$ was 4.42 , the sensitivity was $79.3 \%$, and the specificity was $50.0 \%$. 


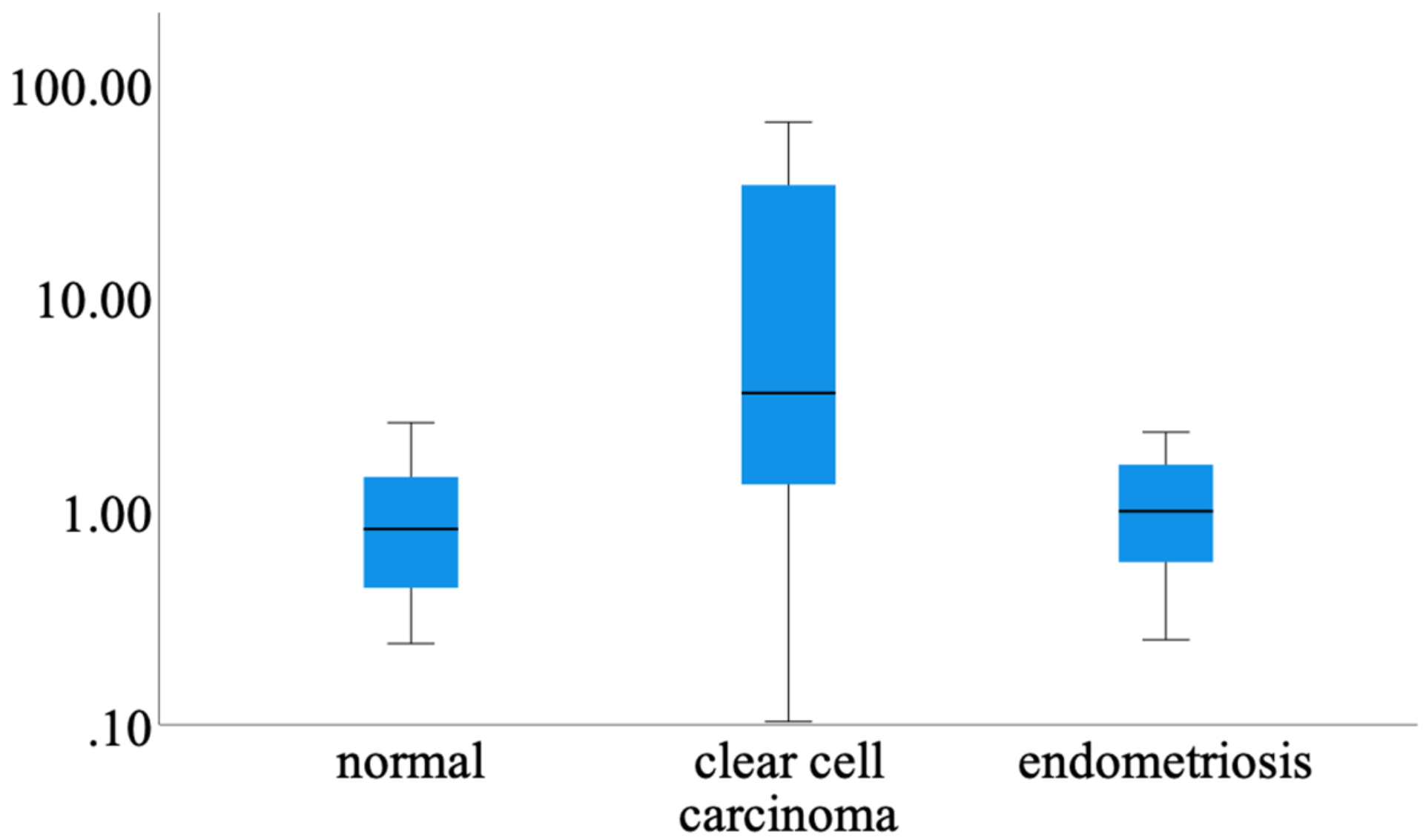

Figure 5

The serum miR 191-5p expression level in subjects The serum miR 191-5p expression levels in the subjects with ovarian clear cell carcinoma and ovarian endometriosis at various stages by a quantitative polymerase chain reaction. The asterisk indicates statistical difference $(P<0.05)$ is significant. 


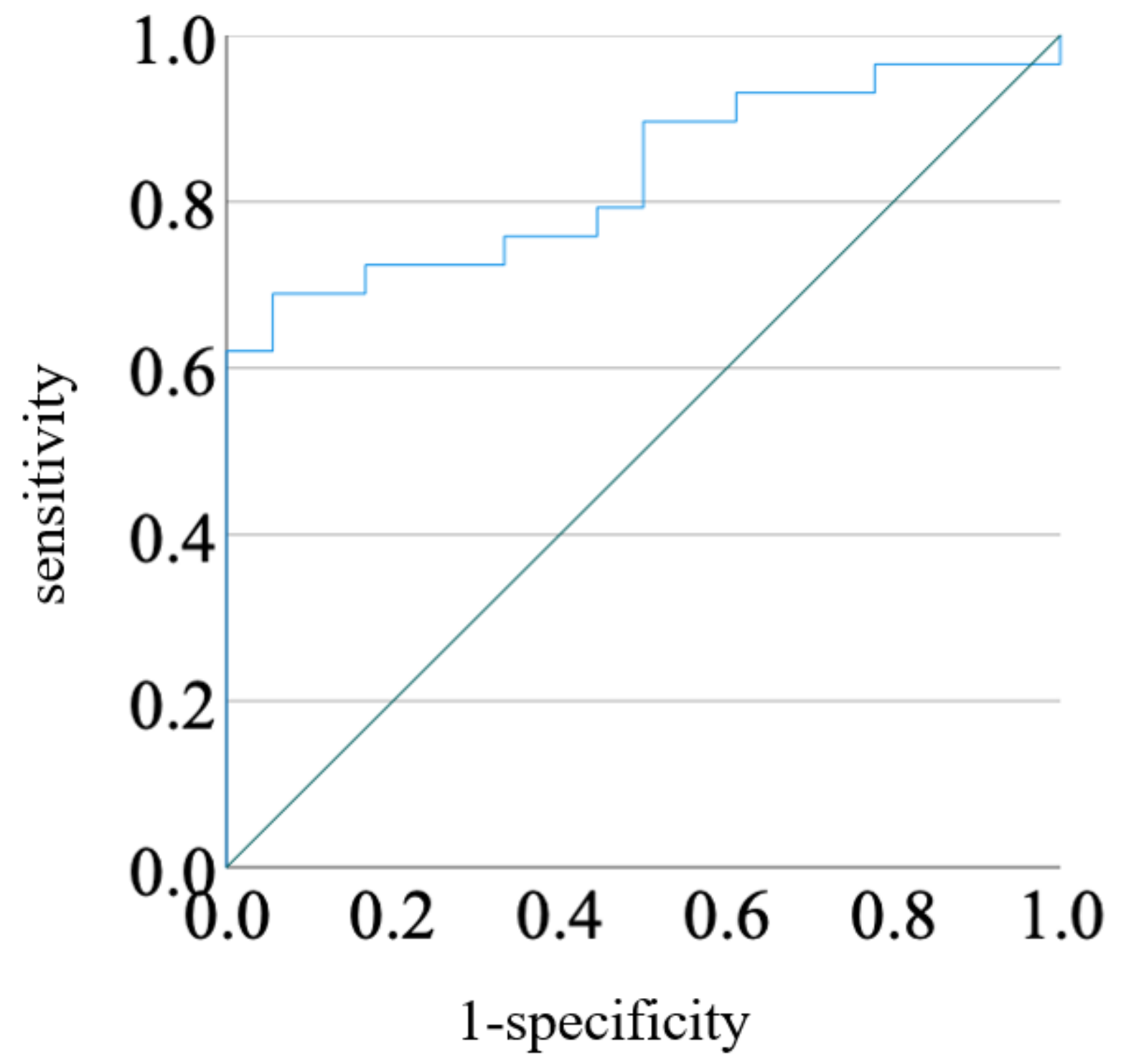

Figure 6

ROC for miR-191-5p in the normal and ovarian clear cell carcinoma The area under the receiver operating characteristic curve for miR 191-5p based on quantitative polymerase chain reaction data. The cut-off level of plasma miR $191-5 p$ was 3.58 , the sensitivity was $89.7 \%$, and the specificity was $50.0 \%$.

\section{Supplementary Files}

This is a list of supplementary files associated with this preprint. Click to download.

- EAZAW13Additionalfile1.xls 